\title{
Fatores que contribuem para a ocorrência da violência obstétrica no Brasil: revisão integrativa de literatura
}

\author{
Factors that contribute to the occurrence of obstetric violence in Brazil: integrative \\ literature review
}

Factores que contribuyen a la ocurrencia de violencia obstétrica en Brasil: revisión bibliográfica integradora

\begin{abstract}
Sara Cristina Santos Ferreira ${ }^{1 *}$, Nívea Keyze Cardoso Pantoja ${ }^{1}$, Lucas Bezerra Silva ${ }^{1}$, Ananda Caroline Pires Torres ${ }^{1}$, Elyade Nelly Pires Rocha².
\end{abstract}

\section{RESUMO}

Objetivo: Fazer um levantamento bibliográfico para determinar quais os fatores que influenciam a ocorrência da violência obstétrica no Brasil. Métodos: Trata-se de uma Revisão Integrativa da Literatura, a qual incluiu artigos de Língua Portuguesa dos anos de 2017, 2018 e 2019, por meio das bases de dados SCIELO, BDENF e LILACS, mediante os descritores: Violência, violência de gênero, trabalho de parto, ocorrência e influência. Foram excluídos relatos de caso, teses e documentos que não enquadravam-se no delineamento da pesquisa. Resultados: Foram identificados argumentos no que tange à ideia de hierarquização profissional-paciente, de preceitos étnicos no momento do processo parturitivo, da percepção médica/profissional acerca do parto, da espera de um atendimento deficiente em serviços públicos de saúde, de condições extenuantes de trabalho dos profissionais e de restrições ao acompanhante de escolha da parturiente como grandes influentes dos casos de violência obstétrica. Considerações finais: Fatores sociais, econômicos e culturais influenciam na ocorrência de violência obstétrica; portanto, para assegurar uma prática assistencial de qualidade, torna-se necessário uma melhor aplicação de medidas que visem e assegurem proteção dos direitos, da integridade e da vida de gestantes e infantes.

Palavras-chave: Violência, Influência, Trabalho de parto, Violência de gênero, Ocorrência.

\begin{abstract}
Objective: Make a bibliographic survey to determine which factors influence the occurrence of obstetric violence in Brazil. Methods: This is an Integrative Literature Review, which included articles of Portuguese Language from the years 2017, 2018 and 2019, through the databases SCIELO, BDENF and LILACS, using the descriptors: Violence, gender violence, occurrence and influence. Case reports, theses and documents that did not fit the research design were excluded. Results: Arguments were identified regarding the idea of professional-patient hierarchy, ethnic precepts at time of the parturition process, medical/professional perception about childbirth, waiting for poor care in public health services, strenuous conditions of professionals's work and restrictions on the companion of the parturient's choice as major influencers in cases of obstetric violence. Final considerations: Social, economic and cultural factors influence the occurrence of obstetric violence; therefore, to ensure a quality care practice, it is necessary to better apply measures aimed at and ensuring protection of the rights, integrity and life of pregnant women and infants.
\end{abstract}

Keywords: Violence, Influence, Labor, Gender violence, Occurrence.

1 Universidade da Amazônia (UNAMA), Belém - PA. *E-mail: srcristina80@gmail.com

2 Universidade Federal do Pará (UFPA), Belém - PA. 


\section{RESUMEN}

Objetivo: Realizar una revisión de la literatura para determinar qué factores influyen en la ocurrencia de violencia obstétrica en Brasil. Métodos: Se trata de una Revisión de Literatura Integrativa, que incluyó artículos en portugués de los años 2017, 2018 y 2019, a través de las bases de datos SCIELO, BDENF y LILACS, utilizando los descriptores: Violencia, violencia de género, laboral, ocurrencia e influencia. Se excluyeron casos clínicos, tesis y documentos que no se ajustaran al diseño de la investigación. Resultados: Se identificaron argumentos sobre la idea de jerarquía profesional-paciente, preceptos étnicos en el momento del proceso de parto, percepción médico / profesional sobre el parto, espera de atención deficiente en los servicios de salud pública, condiciones de trabajo agotadoras de los profesionales y restricciones. sobre la elección del acompañante de la parturienta como grandes influyentes en casos de violencia obstétrica. Consideraciones finales: Los factores sociales, económicos y culturales influyen en la ocurrencia de violencia obstétrica; por lo tanto, para asegurar una práctica asistencial de calidad, es necesario aplicar mejor las medidas dirigidas y asegurar la protección de los derechos, la integridad y la vida de las mujeres embarazadas y del lactante.

Palabras Clave: Violencia, Influencia, Trabajo de parto, Violencia de género, Ocurrencia.

\section{INTRODUÇÃO}

O parto trata-se de uma das experiências mais importantes da vida de uma mulher, isso porque o processo gravídico-puerperal trata-se de processo natural e fisiológico onde ocorre uma diversidade de mudanças físicas, mentais, sociais e etc, configurando-se assim como um momento permeado por dúvidas, conflitos e sentimentos diversificados, portanto, é de conhecimento geral que corresponde a um período de extrema necessidade de uma assistência de qualidade que forneça acolhimento e cuidados, entretanto, a problemática surge quando este cenário é alterado devido à casos de injúria à figura da mulher e a de seu processo parturitivo (OLIVEIRA MC e MERCES MC, 2017).

Com o passar dos anos, o parto passou a ser entendido como patológico devido a institucionalização da assistência, transformando assim a prática em algo mais técnico e intervencionista e menos humanizado gerando a utilização de técnicas não recomendadas e desnecessárias que tem consequências diretas na saúde da mulher e do bebê, aumentando o risco do surgimento de feridas físicas e psicológicas irreparáveis, tornando esta experiência uma das mais traumatizantes de ser vivida, além de contribuir para as altas taxas de morbimortalidade materna e perinatal (JARDIM DMB e MODENA CM, 2018).

Pesquisas apontam que cerca de $25 \%$ das mulheres brasileiras que passaram pelo processo de parto, tanto em instituições públicas quanto privadas, relatam algum tipo de violência variando de violências verbais à violência física, além de violência de cunho sexual. A pesquisa 'Nascer no Brasil' avaliou 266 hospitais de 191 municípios do país e encontrou altos índices de realização de procedimentos não recomendados como episiotomia (56\%), privação de alimentos durante o trabalho de parto $(70 \%)$, posição litotômica (92\%), manobra de Kristeller (37\%) e taxas baixas de boas práticas, como a presença constante de um acompanhante (18\%) (PALHARINI LA, 2017; LANSKY S, et al., 2017; SENS MM e STAMM AMNF, 2019).

Considera-se como Violência Obstétrica (VO), de acordo com a Organização Mundial da Saúde (OMS), intervenções desnecessárias na parturiente e no recém-nascido (como aceleração do trabalho de parto; realização de episiotomia, manobras mecânicas), agressões físicas e verbais, ambientação inadequada, não acato aos anseios da gestante, compartimentalização ou negação de informações à mulher e qualquer tipo de discriminação que envolva questões culturais, religiosas, econômicas e sociais, etc (LANSKY S, et al., 2019).

$\mathrm{Na}$ atualidade, ressalta-se o fato de que há mulheres em situações de maior exposição à esta injúria, sendo estas de grupos étnicos minoritários, de classes menos favorecidas, de menor escolaridade, de 
situações de vivência nas ruas e as sem acompanhante nos vários estágios do parto. Ademais, a carência de qualidade na assistência, refletida na falta de comunicação entre pacientes, familiares e profissionais da saúde, na evidente hierarquia nas relações profissional-paciente também influenciam estas ocorrências (PEDROSO CNLS e LÓPEZ LC, 2017; KOPERECK CS, et al., 2018; JARDIM DMB e MODENA CM, 2018; SENS MM e STAMM AMNF, 2019).

Ressaltando-se o fato de que muitas parturientes alegam já esperar um atendimento deficiente em serviços públicos de saúde, o que envolve a desvalorização de sua opinião e a carência de métodos mais apropriados ao parto, de acordo com Sens MM e Stan AMNF (2019). E, em contrapartida, há os profissionais de saúde que atribuem atos de assistência deficitária às exaustivas condições de trabalho, onde tem-se uma significativa demanda por atendimento para poucos leitos e estrutura hospitalar inadequada (OLIVEIRA VJ e PENNA, 2017).

Diante do cenário atual da assistência de saúde ao parto, a mulher e ao bebê no Brasil é de grande importância que as diversas entidades governamentais e não governamentais estejam dispostas a adotar estratégias de políticas públicas de saúde cujo objetivo seja garantir a melhoria no acesso, cobertura e qualidade do acompanhamento pré-natal, parto e puerpério, com atenção humanizada à mulher e à criança, na perspectiva dos direitos de cidadania, conforme evidencia Oliveira MC e Merces MC (2017) e Costa RLM (2018), como forma de prevenir os diversos tipos de violências nas práticas de saúde e, por conseguinte, reduzir os índices de morbimortalidade materna e perinatal no mundo. Por isso, a necessidade de programas como a Rede Cegonha, Programa de Humanização no Pré-Natal e Nascimento e as casas de partos vinculadas ao Sistema Único de Saúde (SILVA MC, et al., 2018).

Com isto, esta pesquisa teve como objetivo levantar as principais abordagens atuais que evidenciam aspectos influentes nos casos de violência no trabalho de parto, parto e pós-parto no Brasil.

\section{MÉTODOS}

Trata-se de uma Revisão Integrativa da Literatura, a qual possibilita a inclusão de estudos de abordagens variadas, combinando dados da literatura teórica e empírica, além de agregar desígnios como: definição de conceitos, revisão de teorias e análise de problemas. A revisão baseia-se em seis etapas: elaboração da pergunta norteadora; busca na literatura; coleta de dados; análise dos estudos selecionados; discussão acerca dos resultados e, por fim, apresentação da revisão integrativa (JARDIM DMB e MODENA CM, 2018).

O presente estudo teve como objetivo responder à questão norteadora: quais fatores contribuem para a ocorrência da Violência Obstétrica no Brasil?. A coleta de dados foi realizada nas bibliotecas virtuais: Scientific Electronic Library Online (SCIELO) e Biblioteca Virtual em Saúde (BVS) com acesso à Base de Dados de Enfermagem (BDENF) e Literatura Latino-Americana e do Caribe em Ciências da Saúde (LILACS). Por meio dos descritores: Violência, Influência, Trabalho de parto, Violência de gênero e Ocorrência.

Os critérios de inclusão foram: artigos totalmente brasileiros, em Língua Portuguesa e, devido ao maior acervo literário referente ao tema que norteia a pesquisa em questão ter sido encontrado dentro deste período, publicados entre os anos de 2017, 2018 e 2019, nos formatos de artigo e artigo de revisão. E, para critérios de exclusão, envolveu-se os documentos de cunho específico, que não necessariamente respondiam ao problema de pesquisa e os que não enquadravam-se no delineamento do estudo.

Conforme a Figura 1, a qual representa um fluxograma com os passos das etapas de busca na literatura e coleta de dados, foram exploradas as bases de dados SciELO, BDEnf e LILACS, das quais no total obteve-se um resultado de 132 publicações cujos títulos e resumos foram lidos e avaliados e, de acordo com os critérios de seleção, foram excluídas 112 publicações. Os dados foram recolhidos no período entre Agosto e Setembro de 2019, incluindo-se por fim 20 publicações que abordam a temática da pesquisa. 
Figura 1 - Fluxograma com seleção dos artigos para revisão.

Quais os fatores que contribuem para a ocorrência da Violência Obstétrica no Brasil?

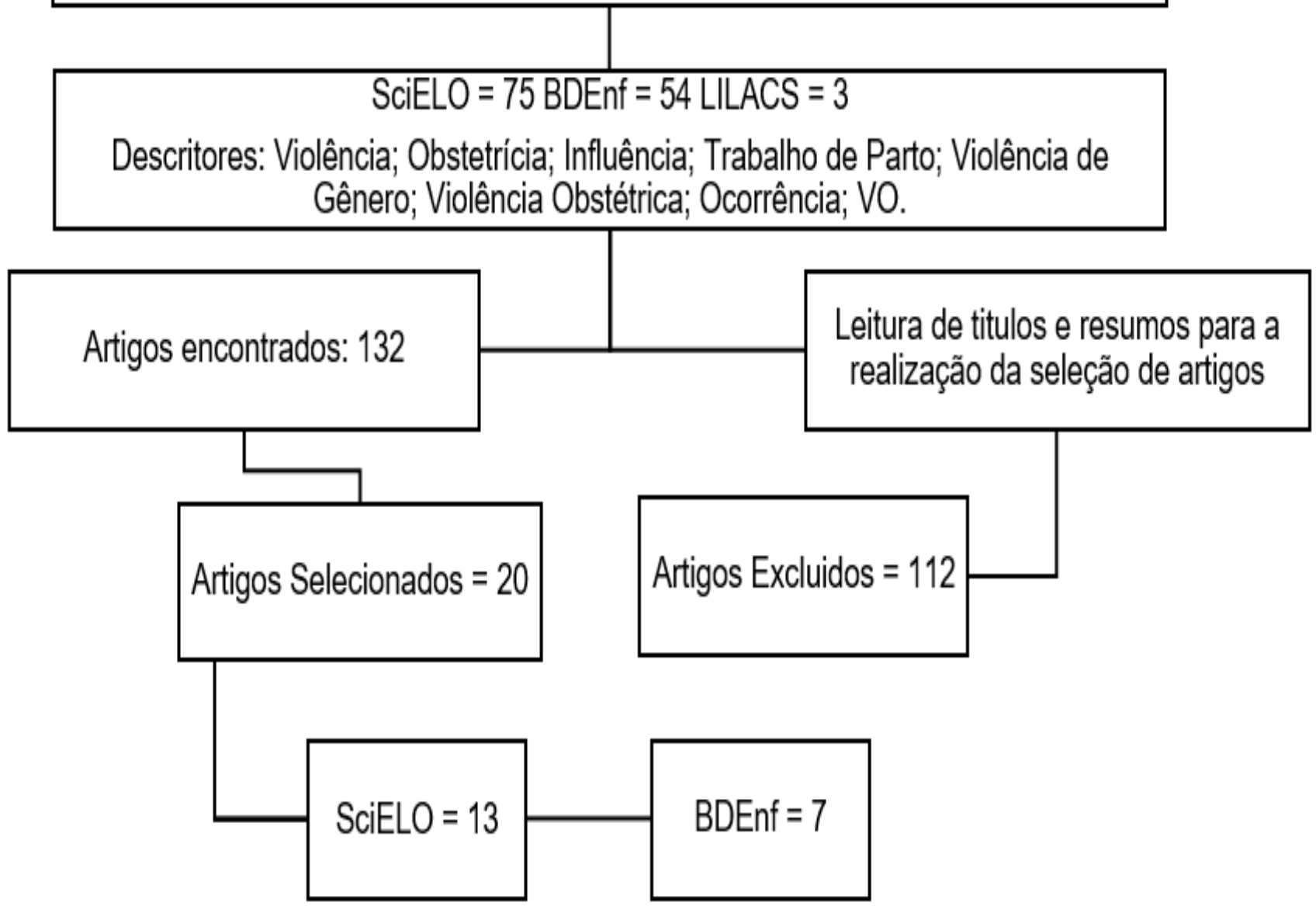

Fonte: FERREIRA SCS, et al., 2021.

Mediante a análise e interpretação dos dados selecionados, obteve-se fundamentos para a elaboração do corpo do artigo, resultando em dois tópicos principais: Perfil dos Artigos e Fatores que Contribuem Para a Ocorrência da Violência Obstétrica no Brasil.

\section{RESULTADOS}

\section{Perfil dos Artigos Selecionados}

Depois da seleção e análise das 20 publicações inclusas, verificou-se que os artigos divulgados distribuíram-se de maneira numericamente aproximada nos anos de 2017 (8), 2018 (7) e 2019 (5). Em relação ao idioma dos documentos analisados, todos (100\%) foram em língua portuguesa, com os desenhos dos estudos de natureza qualitativa (15 artigos), quantitativa (2 artigos) e revisão de literatura (3 artigos) (Quadro 1).

Para melhor visualização dos artigos que compuseram o presente estudo, construiu-se uma tabela composta por informações pertinentes como: título, autor/ano, propostas dos respectivos autores e os principais achados dos estudos. 
Quadro 1 - Síntese das publicações referenciadas neste artigo.

\begin{tabular}{|c|c|c|c|}
\hline Título & Autor / Ano & Proposta & Principais Achados \\
\hline $\begin{array}{c}\text { A percepção dos médicos sobre as } \\
\text { dimensões da violência obstétrica } \\
\text { e/ou institucional. }\end{array}$ & $\begin{array}{l}\text { Sens MM e Stamm } \\
\text { AMNF (2019). }\end{array}$ & $\begin{array}{l}\text { Analisar o ponto de vista de médicos de } \\
\text { uma maternidade pública do sul do Brasil } \\
\text { acerca da Violência Obstétrica }\end{array}$ & $\begin{array}{l}\text { A nomenclatura Violência Obstétrica é considerada desagradável } \\
\text { pelos participantes. Além de relacionarem a VO à prática } \\
\text { desatualizada, à negligência profissional e as condições oferecidas } \\
\text { pela instituição. }\end{array}$ \\
\hline $\begin{array}{l}\text { Violência obstétrica: influência da } \\
\text { Exposição Sentidos do Nascer na } \\
\text { vivência das gestantes. }\end{array}$ & $\begin{array}{l}\text { Lansky S, } \\
\text { et al. (2019). }\end{array}$ & $\begin{array}{l}\text { Avaliar a experiência de parto e da } \\
\text { percepção sobre Violência Obstétrica das } \\
\text { mulheres que compareceram na } \\
\text { exposição. }\end{array}$ & $\begin{array}{l}\text { O estudo constatou que os relatos sobre VO se relacionam à } \\
\text { práticas obsoletas de saúde e à população de menor renda. Além de } \\
\text { que a exposição aumentou o conhecimento acerca do assunto das } \\
\text { mulheres que participaram. }\end{array}$ \\
\hline $\begin{array}{l}\text { Interseccionalidade, racismo } \\
\text { institucional e direitos humanos: } \\
\text { compreensões à violência } \\
\text { obstétrica. }\end{array}$ & Assis JF (2018). & $\begin{array}{l}\text { Evidenciar conceitos para uma melhor } \\
\text { compreensão acerca da Violência } \\
\text { Obstétrica cometida contra mulheres } \\
\text { negras. }\end{array}$ & $\begin{array}{l}\text { O saber biomédico excedente tende a desconsiderar a opinião das } \\
\text { parturientes, o baixo investimento em políticas públicas, as } \\
\text { hierarquias de gênero e etnia, são alguns fatores que proporcionam } \\
\text { a ocorrência da VO, principalmente contra mulheres negras que são } \\
\text { as mais afetadas, bem como as de baixas renda e escolaridade. }\end{array}$ \\
\hline $\begin{array}{l}\text { A violência obstétrica no cotidiano } \\
\text { assistencial e suas características. }\end{array}$ & $\begin{array}{l}\text { Jardim DMB e } \\
\text { Modena CM } \\
\quad(2018)\end{array}$ & $\begin{array}{l}\text { Avaliar o que a literatura possui até então } \\
\text { relacionado à Violência Obstétrica e } \\
\text { discutir suas principais características. }\end{array}$ & $\begin{array}{l}\text { Evidenciou-se que a VO é uma violação aos direitos humanos e um } \\
\text { sério problema de saúde pública, por meio de negligência, omissões } \\
\text { e discriminações praticadas por profissionais de saúde. }\end{array}$ \\
\hline $\begin{array}{l}\text { Violência obstétrica em } \\
\text { maternidades públicas do estado } \\
\text { do Tocantins. }\end{array}$ & $\begin{array}{l}\text { Guimarães LBE, et } \\
\text { al. } \\
\text { (2018). }\end{array}$ & $\begin{array}{l}\text { Analisar a acuidade de mulheres que } \\
\text { vivenciaram o processo de parto sobre a } \\
\text { Violência Obstétrica. }\end{array}$ & $\begin{array}{l}\text { Parturientes identificaram a VO como a falta de qualidade na } \\
\text { assistência, por meio de negligência, violências física, verbal e } \\
\text { psicológica. Além do descumprimento de políticas e práticas } \\
\text { obsoletas. }\end{array}$ \\
\hline $\begin{array}{l}\text { Parto e nascimento na região rural: } \\
\text { a violência obstétrica. }\end{array}$ & $\begin{array}{l}\text { Silva MC, } \\
\text { et al. (2018). }\end{array}$ & $\begin{array}{l}\text { Explorar as formas de Violência } \\
\text { Obstétrica no parto e pós-parto. }\end{array}$ & $\begin{array}{l}\text { Foram identificadas diversas formas de } \mathrm{VO} \text {, como abuso verbal, } \\
\text { discriminação racial, abandono, negligência e recusa de assistência. }\end{array}$ \\
\hline $\begin{array}{l}\text { A violência obstétrica no contexto } \\
\text { do parto e nascimento. }\end{array}$ & $\begin{array}{l}\text { Rodrigues DP, et } \\
\text { al. (2018). }\end{array}$ & $\begin{array}{l}\text { Analisar ações consideradas violentas na } \\
\text { obstetrícia. }\end{array}$ & $\begin{array}{l}\text { A VO está presente em práticas profissionais como a episiotomia, a } \\
\text { manobra de Kristeller e a medicalização do parto. }\end{array}$ \\
\hline
\end{tabular}




\begin{tabular}{|c|c|c|c|}
\hline Título & Autor / Ano & Proposta & Principais Achados \\
\hline $\begin{array}{l}\text { Percepções de mulheres que } \\
\text { vivenciaram a } \\
\text { peregrinação anteparto na rede } \\
\text { pública hospitalar. }\end{array}$ & Costa RLM (2018). & $\begin{array}{l}\text { Avaliar a percepção de parturientes que } \\
\text { peregrinaram em busca de leitos na rede } \\
\text { pública de saúde. }\end{array}$ & $\begin{array}{l}\text { As principais percepções e inquietações vivenciadas pelas mulheres } \\
\text { foram o medo de parir em via pública, sensação de abandono e falta } \\
\text { de acolhimento, dentre outros que permitiram investigar sobre o } \\
\text { quanto mulheres ainda sofrem por atendimento em portas de } \\
\text { maternidades no país. }\end{array}$ \\
\hline $\begin{array}{l}\text { A violência obstétrica no contexto } \\
\text { multinacional. }\end{array}$ & $\begin{array}{l}\text { Kopereck CS, et al. } \\
\text { (2018). }\end{array}$ & $\begin{array}{l}\text { Buscar na literatura o que há sobre temas } \\
\text { relacionados à Violência Obstétrica. }\end{array}$ & $\begin{array}{l}\text { No estudo constatou-se que a VO está presente em diversos setores } \\
\text { do cuidado, por isso, sua erradicação tende a ser mais dificultosa. }\end{array}$ \\
\hline $\begin{array}{l}\text { Autonomia para quem? O discurso } \\
\text { médico hegemônico sobre a } \\
\text { violência obstétrica no Brasil. }\end{array}$ & Palharini LA (2017). & $\begin{array}{l}\text { Explorar a percepção da classe médica } \\
\text { hegemônica relacionada ao tema da } \\
\text { Violência Obstétrica. }\end{array}$ & $\begin{array}{l}\text { A pesquisa evidenciou que o discurso médico hegemônico acerca do } \\
\text { parto traduz-se em intervir e prescrever, desconsideração da opinião } \\
\text { da parturiente, autoridade científica, o que provoca alienação do } \\
\text { corpo da mulher e sua experiência no trabalho de parto. }\end{array}$ \\
\hline $\begin{array}{l}\text { À margem da humanização? } \\
\text { Experiências de parto de usuárias } \\
\text { de uma maternidade pública de } \\
\text { Porto Alegre-RS. }\end{array}$ & $\begin{array}{l}\text { Pedroso CNLS e } \\
\text { López LC (2017). }\end{array}$ & $\begin{array}{l}\text { Externar sobre a vivência de parturientes } \\
\text { em maternidade pública no sul do Brasil. }\end{array}$ & $\begin{array}{l}\text { As parturientes perceberam a VO como inflexibilidade dos protocolos } \\
\text { de atendimento, supervalorização de práticas tecnológicas em seu } \\
\text { corpo, hierarquia entre profissional e paciente, e banalização de } \\
\text { práticas violentas pelas próprias mulheres que consideravam já } \\
\text { esperar este tipo de atendimento da rede pública. }\end{array}$ \\
\hline $\begin{array}{l}\text { O descumprimento da Lei do } \\
\text { Acompanhante como agravo à } \\
\text { saúde pública. }\end{array}$ & $\begin{array}{l}\text { Rodrigues DP, } \\
\text { et al. (2017). }\end{array}$ & $\begin{array}{l}\text { Analisar o conhecimento de parturientes } \\
\text { acerca da Lei do Acompanhante, seu } \\
\text { descumprimento e suas experiências. }\end{array}$ & $\begin{array}{l}\text { As participantes relataram o descumprimento da lei nas instituições } \\
\text { em que estiveram e pelos profissionais que as atenderam, } \\
\text { provocando estresses, desgastes e tensões entre os envolvidos. } \\
\text { Além de que o estudo também evidenciou esta ocorrência se dá pela } \\
\text { falta de conhecimento acerca da lei pelas parturientes e familiares. }\end{array}$ \\
\hline $\begin{array}{l}\text { Violência Obstétrica no Brasil: } \\
\text { Revisão Narrativa. }\end{array}$ & $\begin{array}{l}\text { Zanardo GLP, et al. } \\
\text { (2017). }\end{array}$ & $\begin{array}{l}\text { Realizar revisão narrativa sobre } \\
\text { documentos que abordem a Violência } \\
\text { Obstétrica. }\end{array}$ & $\begin{array}{l}\text { Práticas estereotipadas de submissão da mulher, adicionadas às } \\
\text { ideologias médicas hegemônicas e de gênero favorecem a } \\
\text { ocorrência da VO, além de rotinas e ambientes extenuantes a que } \\
\text { profissionais estão expostos. }\end{array}$ \\
\hline $\begin{array}{l}\text { O discurso da violência obstétrica } \\
\text { na voz das mulheres e dos } \\
\text { profissionais de saúde. }\end{array}$ & $\begin{array}{l}\text { Oliveira VJ e Penna } \\
\text { CMM (2017). }\end{array}$ & $\begin{array}{l}\text { Apresentar o ponto de vista de mulheres } \\
\text { e profissionais da saúde acerca da } \\
\text { assistência ao parto. }\end{array}$ & $\begin{array}{l}\text { O discurso da VO expressa-se no silêncio dos profissionais ao } \\
\text { presenciarem uma hostilidade, justificativa da agressão por parte das } \\
\text { mulheres e dos profissionais, aquelas por acharem que faz parte do } \\
\text { processo natural e, estes, por acreditarem ser um caso isolado que } \\
\text { não provoque grandes magnitudes. }\end{array}$ \\
\hline
\end{tabular}




\begin{tabular}{|c|c|c|c|}
\hline Título & Autor / Ano & Proposta & Principais Achados \\
\hline $\begin{array}{c}\text { Percepções sobre violências } \\
\text { obstétricas na ótica de Puérperas. }\end{array}$ & $\begin{array}{c}\text { Oliveira MC e } \\
\text { Merces MC (2017). }\end{array}$ & $\begin{array}{l}\text { Avaliar o conhecimento de puérperas } \\
\text { acerca das formas de Violência } \\
\text { Obstétrica. }\end{array}$ & $\begin{array}{l}\text { O estudo evidenciou que há o desconhecimento acerca dos tipos de } \\
\text { VO pelas parturientes, tendo estas uma percepção restrita à } \\
\text { violência verbal, física, sexual e à negligência. }\end{array}$ \\
\hline $\begin{array}{l}\text { Violência obstétrica no processo de } \\
\text { parturição em maternidades } \\
\text { vinculadas à Rede Cegonha }\end{array}$ & $\begin{array}{l}\text { Rodrigues FAC, et } \\
\text { al. } \\
\text { (2017). }\end{array}$ & $\begin{array}{l}\text { Avaliar a Violência Institucional contra } \\
\text { parturientes da Rede Cegonha de } \\
\text { Fortaleza. }\end{array}$ & $\begin{array}{l}\text { O estudo demonstrou que há práticas enraizadas e tanto } \\
\text { ultrapassadas nas instituições vinculada à Rede Cegonha, os quais } \\
\text { ocasionam traumas físicos e psicológicos, constrangimentos e } \\
\text { gastos, que banalizam a VO, impedindo a interrupção de seu ciclo. }\end{array}$ \\
\hline $\begin{array}{l}\text { Violência obstétrica: Revisão } \\
\text { integrativa de pesquisas } \\
\text { qualitativas. }\end{array}$ & $\begin{array}{l}\text { Barbosa LC, et al. } \\
\qquad(2017)\end{array}$ & $\begin{array}{l}\text { Explanar como alguns fatores podem } \\
\text { interferir na boa assistência ao parto. }\end{array}$ & $\begin{array}{l}\text { Práticas desatualizadas e vistas como normais por profissionais e/ou } \\
\text { pacientes, autoritarismo profissional, desrespeito à figura da mulher } \\
\text { e não autonomia da parturiente foram alguns fatores evidenciados } \\
\text { como entrave a um bom manejo do parto. }\end{array}$ \\
\hline $\begin{array}{l}\text { O funcionamento discursivo de } \\
\text { campanhas sobre a violência no } \\
\text { parto: testemunhas, violência e } \\
\text { silêncio. }\end{array}$ & $\begin{array}{l}\text { Bocchi AFA, et al. } \\
\text { (2018). }\end{array}$ & $\begin{array}{l}\text { Refletir formas de significar a Violência } \\
\text { Obstétrica atualmente. }\end{array}$ & $\begin{array}{l}\text { O trauma vivenciado por parturientes que sofreram } \mathrm{VO} \text {, ao invés de } \\
\text { silenciado por constrangimentos ou falta de conhecimentos, deve ser } \\
\text { contado como uma forma de quebrar o esquecimento político e } \\
\text { ajudar na construção ou aprimoramento de políticas contra este tipo } \\
\text { de violência }\end{array}$ \\
\hline $\begin{array}{l}\text { Conhecimentos e experiências de } \\
\text { Violência Obstétrica em mulheres } \\
\text { que vivenciaram a experiência do } \\
\text { parto }\end{array}$ & $\begin{array}{l}\text { Nascimento SL, et } \\
\text { al. (2019). }\end{array}$ & $\begin{array}{l}\text { Avaliar o conhecimento de mulheres que } \\
\text { vivenciaram a Violência Obstétrica e suas } \\
\text { formas no parto. }\end{array}$ & $\begin{array}{l}\text { O estudo evidenciou que algumas parturientes desconhecem o } \\
\text { significado de VO, outras relatam que sofreram agressões verbais e } \\
\text { que foram submetidas a procedimentos invasivos não consentidos } \\
\text { durante o trabalho de parto. }\end{array}$ \\
\hline $\begin{array}{l}\text { Um corte na alma: como } \\
\text { parturientes e doulas significam a } \\
\text { violência obstétrica que } \\
\text { experienciam. }\end{array}$ & $\begin{array}{l}\text { Sampaio J, et al. } \\
\text { (2018). }\end{array}$ & $\begin{array}{l}\text { Avaliar como parturientes e doulas } \\
\text { entendem Violências Obstétricas que } \\
\text { vivenciam. }\end{array}$ & $\begin{array}{l}\text { Neste estudo foram evidenciados objetificação do corpo da mulher, } \\
\text { hierarquização profissional-paciente, anulação da autonomia da } \\
\text { mulher, desejo pela mulher de como seria seu parto foi visto como } \\
\text { desacato, além do abandono como punição. }\end{array}$ \\
\hline
\end{tabular}

Fonte: Ferreira SCS, et al., 2021. 
Conforme análise, foram identificados argumentos de hierarquização profissional-paciente, de preceitos étnicos no momento do processo parturitivo, da percepção profissional acerca do parto, da espera de um atendimento deficitário em serviços públicos de saúde, de condições extenuantes de trabalho dos profissionais e de restrições ao acompanhante de escolha da parturiente.

\section{DISCUSSÃO}

\section{Um Breve Estudo Sobre Violência Obstétrica}

Sabe-se que gerar uma vida e trazê-la ao mundo envolve atenção e cuidado, portanto, qualquer intervenção que influencie de maneira negativa no processo, pode gerar precedentes ao que então chamase de VO. Esta consiste em todo tipo de violação que ocorra durante o processo de gestação, parto, pósparto e assistência em casos de aborto. O modelo de assistência ao parto no Brasil tem contribuído bastante para a ocorrência da mesma, por ser realizado de maneira instrumentalizada e sumamente intervencionista (BARBOSA LC, et al., 2017).

À princípio, percebe-se que em todos os documentos analisados, há variações argumentativas relacionadas em como denominar de forma mais apropriada a chamada "violência obstétrica". Esta é, dentre outros termos, chamada de Violência Institucional no parto (VI) por, principalmente, profissionais médicos. Fato este que vai de encontro à OMS, que conceitua e propaga o termo "Violência Obstétrica", como além de ser uma violência de gênero, ser uma assistência feita de maneira deficitária e desumanizada, refletida no longo tempo de espera para o atendimento, nos maus tratos físicos e verbais, no desrespeito à privacidade e a liberdade de escolhas da mulher, discriminações por razões étnicas e socioeconômicas, dentre outros (GUIMARÃES LBE, et al., 2018).

Diversos estudos apontam para um cenário preocupante de casos de violência obstétrica na assistência ao parto do sistema de saúde brasileiro. Isso porque, segundo a pesquisa realizada pela Fundação Perseu Abramo, estima-se que uma a cada quatro mulheres tenha vivenciado algum tipo de violência durante 0 atendimento ao parto no Brasil. Dentre as situações de violência que são relatadas pode-se citar práticas de toques vaginais violentos ou realizados em excesso, realização de amniotomia de rotina, negação de analgesia, o uso da posição de litotomia, manobra de Kristeller, utilização do fórceps, realização de episiotomia para fins de treino, o uso de ocitocina sintética sem indicação clínica, execução de procedimentos sem o consentimento da mulher e realização de cirurgias cesarianas devido a interesses dos profissionais médicos (NASCIMENTO SL, et al., 2019; SAMPAIO J, et al, 2019).

Importante destacar que a violência obstétrica vai além da realização de procedimentos desnecessários ou inadequados, podendo as gestantes ainda se deparar com falta de uma estrutura adequada, com recursos humanos e físicos escassos ou precários, conforme ressalta Kopereck CS, et al. (2018). Também é importante frisar que essa violência também perpassa pela anulação do direito de escolha da mulher, pelo tratamento rude e grosseiro por meio de violências verbais e não verbais e do desamparo durante essa assistência, assim contribuindo para a destruição de um momento tão singular e levando a parturiente a uma condição traumática onde se prevalece o medo, a insegurança e a insatisfação e possivelmente a uma condição danosa física, mental, social, biológica e etc., de maneira irreversível (ZANARDO GLP, et al., 2017; BOCCHI AFA, et al., 2018; NASCIMENTO SL, et al., 2019).

A ocorrência de casos de violência obstétrica atinge mulheres de todas as etnias, cores, idades, credos, do atendimento público ao privado e, inclusive, de acordo com o tipo de parto, porém, são poucas as mulheres que sabem identificar a ocorrência de determinadas ações como violentas, sendo ainda frequente o desconhecimento desses atos como tal, isso porque elas ainda desconhecem parcial ou totalmente ou tem medo ou não sabem como denunciar tais atos, assim como não tem conhecimento com relação aos seus direitos sexuais e reprodutivos (BARBOSA LC, et al., 2017; BOCCHI AFA, et al., 2018; NASCIMENTO SL, et al., 2019). 
Atualmente no Brasil é notável a existência de uma assistência que apresenta diversos problemas que podem comprometer o cuidado a gestante e ao bebê devido ao fato de que ela está marcada pela falta de uma cultura humanizada, onde nota-se a falta de cuidados dignos e respeitosos, refletindo uma prática mais impessoal onde as parturientes e todas as suas necessidades ficam em segundo plano dando possibilidade à ocorrência de uma experiência negativa para as mesmas, visto que durante o processo gravídicopuerperal, a mulher se encontra em uma situação de vulnerabilidade e necessita de todo suporte e cuidado possível, sendo direito seu o recebimento de informações adequadas sobre seu estado de saúde, num atendimento respeitoso, além de assistência adequada durante o processo do parto, inclusive durante as intervenções a serem realizadas (BARBOSA LC, et al., 2017; NASCIMENTO SL, et al., 2019).

Por isso, nos últimos anos, no Brasil e no mundo, houve uma crescente em discussões, movimentos, atos e campanhas em prol de uma assistência mais humanizada durante o processo parturitivo em virtude do aumento de relatos de violência obstétrica e, por conseguinte, a elevação das taxas de morbimortalidade materna e perinatal, logo, a necessidade de campanhas que apresentem às mulheres leis como lei $n^{\circ}$ 11.108/2005 que ampara o direito da mulher de ter a presença de um acompanhante durante todo o ciclo, além de movimentos como o Movimento pela Humanização do Parto e Nascimento (MHPN) que propõem modificar e ampliar a assistência de maneira que o cuidado seja cuidadoso, respeitoso e igualitário para os envolvidos, assim como outros movimentos propõem medidas que visem a ampliação do cuidado tornandoo mais acolhedor e qualificado, visando bem-estar dos pacientes em detrimento de intervenções técnicas (BARBOSA LC, et al., 2017).

Sendo assim, é necessário identificar os principais fatores para a ocorrência de casos de violência obstétrica e suas consequências, logo, é de grande importância dar visibilidade a esta temática visando a disseminação do conhecimento sobre o assunto visando a melhoria do atendimento realizado pelos profissionais de saúde. Além disso, é importante o repasse de informações adequadas para as pacientes aumentando o conhecimento dos seus direitos e do seu conhecimento com relação as práticas adequadas que devem ser realizadas, assim ajudando a reconhecer possíveis casos de violência e proporcionando uma maior autonomia no processo por meio da participação ativa da mulher e de sua família (LANSKY S, et al., 2019).

\section{Fatores que Contribuem Para a Ocorrência da Violência Obstétrica no Brasil}

Enfatiza-se, à princípio, questões hierárquicas de profissionais sobre gestantes, tendo a prevalência dos conhecimentos técnico-científicos acerca do parto em detrimento da autonomia de escolhas pela mulher. Condição que enfraquece os laços entre as partes, abrindo espaço para as variadas formas de VO. Fatos que acarretam o estabelecimento da ideia histórica de patriarcalismo, que consiste na relação submissa da figura da mulher ao homem, no caso, o profissional de saúde (RODRIGUES DP, et al., 2017).

Paralelamente, expõe-se os relatos do ponto de vista profissional que aponta o parto vaginal tido como mais arriscado à vida/saúde da mãe e do recém-nascido, com a justificativa de que as intervenções sobre o parto são ações necessárias para um correto andamento do processo, cônsono Palharini LA (2017). Porém, práticas tecnológicas podem acarretar em iatrogenias que são direcionadas ao parto em si, culpabilizando-o e naturalizando estas intercorrências como próprias desse processo, fato este que "mascara" o ocorrido, bem como relatado por Zanardo GLP, et al. (2017). Considera-se também, a supervalorização da cesariana pelos profissionais, como um método mais seguro, indolor e propício, o que agrega ainda mais valor à patologização do parto normal, acabando por influenciar as puérperas no seu momento de decisão (KOPERECK CS, et al., 2018; RODRIGUES DP, et al., 2018).

Além disso, o desconhecimento das gestantes acerca de seus direitos sexuais e reprodutivos somado à confiança nas ações dos profissionais que assistem o parto, levam a uma não identificação de possíveis atos violentos. Muitas mulheres que sofreram VO afirmam, ainda, que durante o ocorrido não expressaram questionamentos de indignação quanto as práticas dolorosas e/ou desnecessárias, acreditando serem melhor assistidas caso não "interferissem", gerando situações de total desconforto e insatisfação (OLIVEIRA MC e MERCES MC, 2017). 
Com isso, acreditando-se que uma em cada quatros mulheres brasileiras já sofreram violências durante o parto, atualmente, existem muitas políticas que buscam garantir um cuidado humanizado durante 0 processo, oferecendo a proposta de um ambiente harmonioso para a chegada da criança e para a parturiente. Destaca-se, portanto, a Lei 17.097 de 17/01/2017 sancionada no estado de Santa Catarina, a qual tem por objetivo implantar ações de informação e proteção à gestante e à parturiente em centros de saúde, com o intuito de comunicá-las a respeito do que se trata a VO e como identificá-la (RODRIGUES FAC, et al., 2017).

No entanto, ainda assim, outras práticas de VO persistem, ligadas à questões étnicas e sociais da mulher pois, conforme autores, se esta pertencer à uma minoria étnica, ter menor poder aquisitivo, ter baixa escolaridade, não ter acompanhante e não ter realizado pré-natal, tem maior probabilidade de ser vítima de violência obstétrica. Somando-se a isto, ainda há questões relacionadas à parturiente já esperar um atendimento público deficiente, por possuírem a ideia de que o "comum" destes ambientes envolve sempre assistência e estrutura precárias; fato que as levam a atribuir tanto valor ao suporte que recebem ao ponto de desaperceberem o mau atendimento que Ihes foi prestado (ASSIS JF, 2019).

Além de se perceber nos relatos das usuárias dos serviços de saúde pública, comentários sobre a superlotação de alguns hospitais locais/regionais; o que acarreta na peregrinação da mulher à procura de leitos em outras maternidades, evidenciando-se a dificuldade do Governo em promover uma adequada cobertura da chamada Rede Cegonha que, dentre outras atribuições, assegura um devido transporte da mulher e seus familiares à outras unidades de saúde vinculadas por meio desta rede. Ademais, algumas gestantes também relacionaram os ocorridos de VO com a ausência de um acompanhante de sua escolha; fato demonstrado pela pesquisa Nascer no Brasil, a qual diz que cerca de $24 \%$ das mulheres atendidas em redes públicas/privadas no país, não tiveram a oportunidade de serem acompanhadas por uma pessoa de sua vontade (COSTA RLM, 2018).

Tal situação caracteriza-se como uma violação à Lei Federal 11.108 de 07/04/2005 denominada de Lei do Acompanhante; implantada com o intuito de determinar que os serviços de saúde autorizem a presença de um acompanhante de preferência da mulher durante todo o processo de parto, sendo esta lei, em sua maioria, desconhecida por ambas as partes. Nota-se que a proibição de um acompanhante está relacionada ao discurso de manter a privacidade das parturientes; argumento este que - na verdade - vincula-se à carência estrutural de algumas unidades de saúde que não oferecem quartos privativos à gestante e sua família (LANSKY S, et al., 2019).

Portanto, admite-se que quando se busca assistência profissional em saúde, espera-se encontrar apoio físico e psicológico, informações fidedignas e cuidado capacitado. Porém, o que se percebe atualmente é que os sistemas de saúde falham em alguns aspectos, como: falta de estrutura e recursos e a sobrecarga de demandas nos hospitais e dos profissionais; tudo isto faz com que a assistência tenha características negativistas. Além de que, por razão do desconhecimento da maioria das gestantes de seus direitos, a VO acaba sendo naturalizada. É neste momento que a educação em saúde faz-se sumamente importante (SILVA MC, et al., 2018).

\section{CONSIDERAÇÕES FINAIS}

A violência obstétrica reflete-se nos atos negligentes e discriminatórios, nos sentimentos de superioridade profissional, na banalização de injúrias, nas condições de trabalho exaustivas de trabalhadores de saúde. Com isso, percebe-se que, dentre outras, as Leis 17.097 de 17/01/2017 e 11.108 de 07/04/2005, e a Portaria 569 de 01/06/2000 são importantes e constituem-se como grandes marcos na área da saúde da mulher e da criança, portanto, estas e muitas outras necessitam ser melhor ampliadas, distribuídas e levadas ao conhecimento em todo o país. Por isso, este trabalho contribui para a comunidade científica ao evidenciar os principais fatores que influenciam tal violência de modo que sejam prevenidos ou prontamente identificados e controlados, garantindo uma assistência humanizada ao binômio mãe-filho. 


\section{REFERÊNCIAS}

1. ASSIS JF. Interseccionalidade, racismo institucional e direitos humanos: compreensões à violência obstétrica. Serv. Soc. Soc., 2019; 133: 547-565.

2. BARBOSA LC, et al. Violência obstétrica: Revisão integrativa de pesquisas qualitativas. Avances em enfermeira, 2017; 11(6).

3. BOCCHI AFA, et al. O funcionamento discursivo de campanhas sobre a violência no parto: Testemunho, violência e silêncio. Linguagem em (Dis)curso, 2019; 19(1): 17-33.

4. COSTA RLM. Percepções de mulheres que vivenciaram a peregrinação anteparto na rede pública hospitalar. Revista Baiana de Enfermagem, 2018; 32: 34049.

5. GUIMARÃES LBE, et al. Violência obstétrica em maternidades públicas do estado do Tocantins. Revista Estudos Feministas, 2018; 26(1): e43278.

6. JARDIM DMB, MODENA CM. Obstetric violence in the daily routine of care and its characteristics. Revista LatinoAmericana de Enfermagem, 2018; 26: e3069.

7. KOPERECK CS, et al. A violência obstétrica no contexto multinacional. Revista de Enfermagem, 2018; 12(7): 20502060.

8. LANSKY S, et al. Violência obstétrica: influência da Exposição Sentidos do Nascer na vivência das gestantes. Ciência \& Saúde Coletiva, 2019; 24(8): 2811-2824.

9. NASCIMENTO SL, et al. Conhecimentos e experiências de Violência Obstétrica em mulheres que vivenciaram a experiência do parto. Revista Enfermería Actual, 2019; 37.

10. OLIVEIRA MC, MERCES MC. Percepções sobre violências na ótica de puérperas. Revista de Enfermagem, 2017; $11(6)$.

11. OLIVEIRA VJ, PENNA CMM. O Discurso da Violência Obstétrica Na Voz Das Mulheres e Dos Profissionais de Saúde. Texto \& Contexto - Enfermagem, 2017; 26(2): e06500015.

12. PALHARINI LA. Autonomia para quem? O discurso médico hegemônico sobre a violência obstétrica no Brasil. Cadernos Pagu, 2017; 49: e174907.

13. PEDROSO CNLS, LÓPEZ LC. À margem da humanização? Experiências de parto de usuárias de uma maternidade pública de Porto Alegre-RS. Physis, 2017; 27(4): 1163-1184.

14. RODRIGUES DP, et al. A violência obstétrica no contexto do parto e nascimento. Revista de Enfermagem, 2018; 12(1): 236-246.

15. RODRIGUES DP, et al. O Descumprimento da Lei do Acompanhante Como Agravo à Saúde Obstétrica. Texto \& Contexto- Enfermagem, 2017; 26(3): e5570015.

16. RODRIGUES FAC, et al. Violência obstétrica no processo de parturição em maternidades vinculadas à rede cegonha. Revista Reprodução \& Climatério, 2017; 32(2): 78-84.

17. SAMPAIO J, et al. Um corte na alma: Como parturientes e doulas significam a violência obstétrica que experienciam. Revista Estudos Feministas, 2019; 27(3): e56406.

18. SENS MM, STAMM AMNF. A percepção dos médicos sobre as dimensões da violência obstétrica e/ou institucional. Interface - Comunicação, Saúde, Educação, 2019; 23: e170915.

19. SILVA MC, et al. Parto e nascimento na região rural: a violência obstétrica. Revista de Enfermagem, 2018; 12(9): 2407-2417.

20. ZANARDO GLP, et al. Violência Obstétrica no Brasil: Uma Revisão Narrativa. Psicologia e Sociedade, 2017; 29: e155043. 